\title{
Projection or encounter? Investigating Hans Jonas' case for natural teleology
}

\author{
Sigurd Hverven $^{1}$ D $\cdot$ Thomas Netland $^{1}$
}

Accepted: 27 April 2021 / Published online: 19 May 2021

(c) The Author(s) 2021

\begin{abstract}
This article discusses Hans Jonas' argument for teleology in living organisms, in light of recently raised concerns over enactivism's "Jonasian turn." Drawing on textual resources rarely discussed in contemporary enactivist literature on Jonas' philosophy, we reconstruct five core ideas of his thinking: 1) That natural science's rejection of teleology is methodological rather than ontological, and thus not a proof of its nonexistence; 2) that denial of the reality of teleology amounts to a performative self-contradiction; 3) that the fact of evolution makes it implausible that only humans actualize purpose; 4) that the concept of metabolism delimits and gestures towards beings performing purposive activity; and 5) that concrete encounters with living organisms are indispensable for the judgment that they are purposive. Lastly, we draw attention to how Jonas' understanding of teleology and inwardness in nonhuman life in terms of degrees of identity with human life poses a problem for his view. In this way, we hope to clarify what Jonas, as an important source of inspiration for the enactivist project, is proposing.
\end{abstract}

Keywords Hans Jonas · Teleology $\cdot$ Mind-life continuity $\cdot$ Enactivism $\cdot$ Natural purpose

More than half a century after publication of his seminal book, The Phenomenon of Life (Jonas, 1966), Hans Jonas' existential biology continues to be discussed in a variety of fields, ranging from cognitive science to environmental philosophy. In the former (which is our focus), his influence is mainly felt within the enactive

Sigurd Hverven

sigurd.hverven@ntnu.no

1 Department of Philosophy and Religious Studies, Norwegian University of Science and Technology, Trondheim, Norway 
paradigm. ${ }^{1}$ Here, Jonas' phenomenological interpretation of metabolism in terms of freedom, self-concern, and intrinsic purpose has become a central source of inspiration for enactivism's project of naturalizing the mind by way of the biological notions of autopoiesis and autonomy. In short, here one aims to naturalize the directedness and meaningfulness central to the experiential dimension of mind by rooting it in a view of biological nature as itself normative and purposive.

This "Jonasian turn" in enactivism has been controversial. Some object, stating that the very idea of giving purpose a place in nature is unscientific. Others are sympathetic to the idea but argue that Jonas does more harm than good, insofar as his approach seems committed to a problematic anthropomorphism. ${ }^{2}$ In the following, we will explore the resources Jonas has for responding to these challenges. Importantly, we do not claim that the success of the enactive project is contingent on Jonas' ability to defend himself. Though Jonasian concepts figure centrally in enactivists' accounts of mind-life continuity, these accounts are not "Jonasian" in a dogmatic sense but have evolved significantly beyond their "origin" and rely on their own arguments and research. Nevertheless, we believe that it can be both illuminating and helpful at the current point in enactivist discourse to clarify what Jonas is proposing.

Our main question is: How does Jonas argue for the reality of immanent teleology in living organisms? Here immanent teleology, which we will use interchangeably with intrinsic purpose or just purposiveness, is meant to express the idea of self-generated (hence immanent/intrinsic) aims oriented in light of interests, values, or meanings pertaining to one's form of life. In Jonas, as well as in enactivism, the ascription of immanent teleology to living organisms involves two distinct claims. The most basic is that life is purposive in what Di Paolo labels "the Kantian sense of mutual generative relations" (2005: 433) between the parts of an organism, and between the parts and the organism as a whole, so that the individual living organism is the purpose of its own self-production. The second rests on this idea but goes further by positing that this purposiveness in some sense is manifest for the organism itself, forming an interested or concerned "point of view" (Weber \& Varela, 2002: 116, orig. emphasis). In the enactivist account of these matters, Di Paolo's argument that adaptivity is required in order to make the step from the first claim to the second - which in enactivism amounts to the step from autonomy/autopoiesis to sense-making - represents a significant development (Di Paolo, 2005). ${ }^{3}$ While some (Barrett, 2017) argue that more is required to make this anchoring of subjectivity in

\footnotetext{
${ }^{1}$ Enactive approaches are characterized by an emphasis on the role of embodied activity for cognitive processes. By "enactivism" we think primarily of the position some have labeled "autopoietic enactivism" (Hutto \& Myin, 2013; Ward et al., 2017) due to the significance it gives to the notion of autopoiesis and more generally to the thesis of mind-life continuity. Proponents of the "autopoietic" branch of enactivism have, however, argued that the name is misleading, partly because autopoiesis in their view is only one specific and minimal manifestation of the more general phenomenon of autonomy (e.g. Barandiaran, 2016; Thompson, 2018). One could also argue that the "autopoietic" strand has a special claim to the enactivist name, given that it was researchers of this stripe that coined the phrase in the context of cognitive science in the first place (Varela et al., 1991).

${ }^{2}$ Yet others, like Kee (2018), argue that enactivism should adopt a Merleau-Pontian rather than Jonasian take on mind-life continuity, which in Kee's view has the consequence of reserving the notion of sensemaking for sentient animals.

${ }^{3}$ See also Thompson (2007: 143).
} 
natural processes satisfactory, we will not engage explicitly with this question here. Our concern lies primarily with Jonas' arguments and their reception (and, in some cases, lack thereof) in the enactivist context. We are, however, hopeful that this can bring more clarity to aspects of the more general, contemporary debate on normativity and teleology in enactivism as well.

How can an ascription of teleology to life be justified? One central argument, at least from earlier enactivist texts, is precisely the "anthropomorphic" inference associated with Jonas, namely that it is through experiences of purposive life in ourselves that we become able to recognize teleology in living others. ${ }^{4}$ Another claim is that the science of living systems is able to somehow prove the existence of natural purposes (Di Paolo et al., 2017). While that may be so, it seems that this latter possibility presupposes an idea of what counts as evidence of purposiveness in the first place, which, with the lack of other options, brings us back to the anthropomorphic inference. Even if this might not exhaust the possibilities currently available to enactivists, it seems clear to us that this is an area where more work is needed. ${ }^{5}$ An exploration of Jonas' arguments will hopefully illuminate both hidden challenges to and forgotten resources for establishing teleology in nature.

We have identified and reconstructed five ideas central to Jonas' position. ${ }^{6}$ The first three are negative arguments (refuting or challenging anti-teleological views). Here we respond to Villalobos and Ward's claim (Villalobos \& Ward, 2016) that immanent teleology is incompatible with a naturalistic worldview by outlining Jonas' arguments that natural science's rejection of natural purpose is methodological rather than ontological, and as such not a proof of its non-existence (Section 1), that denial of immanent teleology is a performative self-contradiction (Section 2), and that the fact of our shared evolutionary history makes it prima facie plausible that there is ontological continuity rather than separation between human and nonhuman organisms (Section 3). Further, we examine Jonas' defense against those who are sympathetic to the teleological view of life, but who believe that his philosophy fails to properly establish such a view (Barbaras, 2010; De Jesus, 2015). Specifically, we elaborate and clarify the significance of metabolism in Jonas' argument for immanent teleology (Section 4), and emphasize the role of bodily experience and encounters with others in his account of our ability to grasp the purposiveness of nonhuman organisms (Section 5).

We believe that these five steps together make Jonas' case for natural purpose stronger than what is assumed in contemporary enactivist literature, but we are not under the illusion that his account is flawless. In Section 5 we address what we see as an ambiguity regarding the issue of anthropomorphism that both Jonas and some of his enactivist defenders seem to struggle with. And though we conclude that Jonas has the resources to overcome this ambiguity in favor of a view where the perception

\footnotetext{
4 As we will show later, this reasoning is explicit in Weber and Varela (2002) and at least strongly suggested by Thompson (2007).

5 Enactivist work on empathy, emotions, and perception of others is a more promising option, and bears similarities to some of the resources we find in Jonas. See especially Colombetti (2014).

6 While the enactivist literature on Jonas draws mainly on a couple of chapters of The Phenomenon of Life (1966), our reading is based on a more thorough reading of that book, as well as on his Organism and Freedom (2016), The Imperative of Responsibility (1984), and a couple of shorter articles.
} 
of others is indispensable, we end our paper by drawing attention to an aspect of his account that remains problematic (Section 6): That his criterion for ascribing purposiveness and mind to nonhuman others seems to be based too much on the degree to which they resemble the human, thus overlooking the significance of difference in our encounters with other life forms. In this way, we conclude by highlighting a challenge central to anyone aiming to establish a teleological view of nature.

\section{Science and teleology}

According to Mario Villalobos and Dave Ward, Jonas advocates an "antiscientific" anthropomorphic approach to the examination of life (Villalobos \& Ward, 2016: 205). In short, their argument is that natural science proves that there is no such thing as purpose in (nonhuman) nature, and thus that Jonas' thesis of immanent teleology in living organisms conflicts with scientific evidence and springs from a problematic anthropomorphic projection. Thus, they claim that Jonas "thinks that in the conflict between anthropomorphism and modern science, what is wrong is modern science, not anthropomorphism" (ibid., 207). This, however, is a misrepresentation of Jonas' view. His point is not that philosophers or scientists must "choose between" (ibid.) natural purposes and natural science, or that modern science can only be exercised when an ontology that deprives nature of natural purpose is accepted. This leads us to the first step we have identified in Jonas' case for teleology in nature, which, as mentioned above, is a negative argument: a rejection of the claim that natural science has proven that teleology does not exist in the world. Jonas writes: "Regarding final causes, we must observe that their rejection is a methodological principle guiding inquiry rather than a statement of ascertained fact issuing from inquiry. [...T]he exclusion of teleology is not an inductive result but an a priori prohibition of modern science" (1966: 34).

Jonas' claim is that modern natural science examines nature as if it can be explained by efficient causes alone, but this is a methodological approach, not a result of research. To claim that science demonstrates that the world is devoid of purpose is to confuse methodology with ontology. If science is understood as explaining nature according to laws that make it predictable to humans and facilitated for controlled manipulation, using mathematics as the foremost aid, final causes are outside its scope. As Jonas writes in Organism and Freedom" : "final causes are not measurable and would for this reason alone be outside the scope of scientific verification" (2016: 33).

\footnotetext{
7 In the introduction to The Phenomenon of Life, Jonas says that the systematic statement of his philosophy of organism and life "has yet to reach its final shape" (1966: 6). Yet he published no systematic monograph on the theme during his lifetime. However, more than a decade before the publication of The Phenomenon of Life, Jonas had already formulated a more systematic and worked-through monograph, titled Organism and Freedom. Jonas sent this manuscript to a couple of American publishers, but it was rejected. Therefore, Jonas decided to rework and publish parts of the book in essays that until recently were known as the most fully articulated formulation of his philosophy of organism. In 2016 this original manuscript was published as a part of the collected works of Jonas.
} 
Villalobos and Ward's critique of Jonas seems to rely on the kind of confusion of scientific methodology and ontology - where one makes ontological judgments based on "a methodological principle guiding inquiry" (Jonas, 1966: 34) - that Jonas warns against. The insight lost on Villalobos and Ward can be elaborated as follows: Scientific experiments or examinations (especially physics) are designed to gain insight into (some of) the efficient causes at work in the object; final causes are excluded as a possible "answer" to this specific way of "questioning" the object. This is, of course, a sound and useful approach if the scientist is aware that his/her specific way of "asking" - examining - limits the scope of possible "answers." If s/ he takes the "answers" provided by science to be telling the whole truth about the object in question, however, s/he is guilty of ignorant abstraction, or objectification. For instance, in science's search for lawlike patterns, what is particular in the object - only occurring once, at this point in time and space and never again - is abstracted away. This is necessary and unproblematic as long as one is aware of the level of abstraction, but to mistake such abstractions for concrete objects is a vice of scientism. One of Jonas' philosophical sources can be helpful in elaborating this point: Alfred North Whitehead warns against what he calls "the fallacy of misplaced concreteness" (Whitehead, 1925: 51). The fallacy consists in taking abstractions to be concrete, to confuse the map with the terrain (Griffin, 1998: 117-124). In our view, Villalobos and Ward commit this fallacy by assuming that the natural-scientific picture of the world is the concrete world.

From this we can see that Jonas' openness to natural teleology is not "antiscientific" unless one is committed to the view that only natural-scientific knowledge amounts to proper knowledge about nature. If this kind of scientism is rejected, Jonas' view is compatible with science. His point is, as he writes in The Imperative of Responsibility, that "we should keep ourselves open to the thought that natural science may not tell the whole story about nature" (Jonas, 1984: 8). This view is compatible with saying that natural science tells crucial parts of this story. ${ }^{8}$ Jonas' $^{\text {' }}$ view is antiscientistic, but not antiscientific. Note here that Jonas does not seem to argue that science should incorporate natural purpose in its theories, but rather that we should allow for a sort of pre-scientific knowledge (associated, as we will see later, with concrete bodily experiences of encounter) to inform our natural ontology. In some sense, this is less radical than what we find in contemporary enactivist literature, which, without denying the importance of pre-scientific lived experience, also aims to find a place for natural purpose within a scientific framework. ${ }^{9}$ If it is the case, as these enactivist authors argue, that scientific inclusion of purpose is both possible and fruitful, this would surely pose a further challenge for Villalobos and

\footnotetext{
8 The fact that Jonas makes concepts from natural science, such as "metabolism" and "irritability," central in his philosophical understanding of life indicates that his position in general is not antiscientific.

9 This, after all, is a key element in the enactivist account of autonomy and autopoiesis that was proposed by Weber and Varela (2002) and taken up and further developed by Di Paolo (2005) and Thompson (2007). For a recent, promising enactivist attempt to scientifically ground purposiveness, see Di Paolo et al. (2017). The argument that science needs to somehow incorporate the reality of purpose has also been made outside the enactivist context. For an example of such an argument that even precedes Jonas' writings, see Köhler (1966). For a more recent attempt, see Juarrero (1999).
} 
Ward's purpose-exclusive naturalism, but since this argument is not in Jonas' repertoire, we will not pursue it here.

However, in order to see that the non-teleological picture of the world leaves something out (and hence is an abstraction), Jonas needs an argument for the reality of purposiveness in concrete reality. We get into that from Section 3 onwards. It does, after all, not follow from rejecting that science has proven the non-existence of natural purpose that there in fact is purpose at work in nature, or more specifically in nonhuman organisms.

Let's consider a possible objection to Jonas' claim that science's exclusion of teleology is methodological rather than ontological before we move on to his next argument. Even if we accept that science has not directly disconfirmed the reality of natural purpose, is it not the case that the (apparently) obvious success of its nonteleological approach to explaining and describing reality indirectly means that the concept of teleology is obsolete? This question shifts the burden of proof back to the defenders of the teleological view: Granted that science does fine without the concept of natural purpose, you must tell us why it is still needed. Bracketing the possibility that purpose can operate as a fruitful scientific concept, there are at least two good responses to this objection. The first response, which we will not spend much time on here, is to argue that scientific approaches to life already implicitly presuppose a teleological view. ${ }^{10}$ The second response is to highlight the inconsistency of rejecting the reality of something that is so clearly a presupposition for human activities, which is what Jonas does in the next step we have identified.

\section{Performative self-contradiction}

Here, Jonas tries to establish that the reality of immanent teleology cannot be denied without a practical contradiction. How does he defend this claim?

He does so by revealing the contradiction involved in denying the validity of our own experience of purpose. Jonas makes the point that someone who denies the reality of immanent teleology nonetheless cannot help but act as if what they deny actually is real, and cannot help but approach other humans as if they act with purpose and have the ability to recognize their purposive actions. After all, a human being that tries to defend such an anti-teleological view cannot help but argue with a specific goal in mind: to convince others. But then purposiveness is enacted by the very same subject in the process of denying its existence. This is an example of a performative contradiction - one affirms in practice what one denies in theory. ${ }^{11}$ Hence, Jonas concludes that a human being that takes him or herself seriously and that does not consider him or herself as a unique ontological exception "cannot but

\footnotetext{
10 This is, arguably, Kant's view in Kritik der Urteilskraft (1790), as well as Merleau-Ponty's in Structure of Behavior (1963), and it can also be found in Jonas (see footnote 31).

11 By arguing this way, Jonas seems to agree with Whitehead: "Whatever is found in practice must lie within the scope of the metaphysical description. When the description fails to include practice, the metaphysics is inadequate and requires revision" (Whitehead, 1978: 13).
} 
give nature credit for bringing forth goal-causality, and hence regards the latter as not completely foreign to the former" (Jonas, 1984: 71).

For Jonas, therefore, bodily experiences of being alive are valid testimony of what human life is. First-hand experience is of ontological importance. To deny or ignore this testimony of reality is to deny the closest, most immediate empirical evidence we have. The most influential variant of a view that denies this evidence, according to Jonas, is modern mechanistic materialism. ${ }^{12}$ When taken as a comprehensive ontology, materialism sacrifices this primordial empirical evidence in favor of a generalization of the concept of extended matter, which is based on other experiences and empirical evidence. Thus, as a comprehensive ontology, it is not supported by all the empirical evidence available to us.

With these considerations, Jonas establishes that we must admit that there is such a thing as immanent teleology in the world, at least in human beings. ${ }^{13}$ Here we can briefly note two things. First, it is still possible for the materialist to hold on to a non-teleological view in face of this argument, by insisting that the experience of purpose in human life and communication is a mere illusion. This, however, comes at the price of ultimately denying that any of our utterances are really aimed at communicating anything at all, and hence are completely devoid of meaning, which, besides being highly problematic in itself, seems to lead us back to the charge of self-contradiction. Secondly, while this step in Jonas' argument is surely anthropocentric in the sense that it is exclusively based on human experience, it does not yet amount to anthropomorphism insofar as the ascription of teleology does not extend beyond the human domain.

This step is, in other words, insufficient as an argument for teleology in all organisms. It is still possible to hold that the teleology in human beings is a unique exception, without relevance to the understanding of the rest of nature. This kind of view is more or less explicit in Villalobos and Ward's equation of the positing of teleology in nonhuman organisms with anthropomorphism (Villalobos \& Ward, 2016), ${ }^{14}$ and is stated more directly by Villalobos and Palacios (2019) and Abramova and Villalobos (2015). The challenge that immediately arises here, however, is how to account for this alleged essential difference between human and nonhuman organisms. The

\footnotetext{
12 Jonas conceives of materialism as an account of reality where "blind," "lifeless" matter is regarded as the most real, and where the aspects of reality that can be measured and quantified are conceived as primary. Thus, materialism denies genuine validity to embodied experience of purposive actions. It labels them as purely "subjective" phenomena. Jonas' claim that this is the dominant ontology in modern thinking is supported by more recent studies in philosophy of nature (Evernden, 1993: 18).

13 Jonas only hints at how the purposiveness of the activity of the one solitary human subject is claimed to be evidence of purposiveness in other humans: He points out that the one subject becomes a subject and acquires self-knowledge only as a member of a human community where others are recognized as purposive subjects (Jonas, 1966: 186). His view on this matter is more fully spelled out in the essay "Change and Permanence" (which we comment on in Section 5.3).

14 Villalobos and Ward even claim that "Jonas' philosophy of life has been recognized, [...] by Jonas himself, as an anthropomorphic philosophy" (2016: 205). This ignores Jonas' own warnings against anthropomorphism: "The evidence we find in ourselves is an integral part of the evidence concerning life which experience puts at our disposal. That it must be used critically to avoid the pitfalls of anthropomorphism goes without saying" (Jonas, 1966: 91, our emphasis).
} 
mentioned authors (like many others) do this by pointing to human language as that which enables some sort of teleology to emerge. For instance, in Abramova and Villalobos' view, living beings are "essentially machines composed of chains of deterministic processes" where "any selection or directedness is only in the eye of the observer," but the emergence of language nonetheless assures "a domain in which both content and intentionality have their place" in the life of humans (Abramova \& Villalobos, 2015: 666-667). Although Jonas would agree that language and intersubjective relations enable uniquely human traits, ${ }^{15}$ setting up this sort of absolute difference seems to both ascribe to language an explanatory responsibility it can hardly fulfill, and assume an unjustifiably huge gap between human and nonhuman life. After all, all earthly life shares both a common evolutionary history and core organizational processes (metabolism), and so it seems prima facie reasonable to hold that relations between features of different species are primarily characterized by continuity and difference of degree, rather than of absolute separation. This is the topic of the next two steps of Jonas' argument for natural purpose.

\section{Evolution and continuity}

In order to challenge the view that the evidence of teleology in humans is only valid for the ontological status of human beings, and nothing else, Jonas refers to Darwin's theory of evolution. From Jonas' point of view, Darwin's most important contribution to the understanding of life was to establish "continuity of descent" between humans and other organisms (Jonas, 1966: 57, orig. emphasis). Jonas makes both a negative and a positive argument based on this continuity. Negatively, he claims that the Darwinian case for continuity between humans and other living beings challenges the view that human, purposive being is an ontological exception. One may still argue that there is a leap in the evolutionary development between other animals and humans, a leap from no purposiveness to all purposiveness, but the credibility of such a leap is greatly challenged by the continuity thesis of evolution. To the extent that the two first steps in our reconstruction of Jonas' argumentation for natural purpose are accepted, the Darwinian theory replaces the onus of proof, from the view that there is purposiveness in nature to the view that human purposive life is an exception from an otherwise mechanical and "blind" world of extended matter. In Jonas' words, "evolutionism undid Descartes' work more effectively than any metaphysical critique had managed to do" (ibid.) by making dualism, dividing humans from the rest of nature, incredible as a starting point for philosophical reflection.

Jonas' positive argument goes like this: Against the backdrop of evolutionary relatedness, the evidence from human bodily experience becomes a source of prejudice (in Hans-Georg Gadamer's sense) for interpretation of living beings in general. Jonas writes that in light of the theory of evolution, "the province of 'soul', with feeling, striving, suffering [and] enjoyment [, can be] extended again, by the very principle of continuous graduation, from man over the kingdom of life" (ibid., 57).

15 See Section 5.3. This view is shared by many enactivists. For a recent example, see Gallagher (2020). 
Take notice of the statement of scope here: Jonas draws the line of the emergence of "soul" ("inwardness") and "striving" ("purposiveness") at the beginning of life. Even in the most basic forms of life, even "the single cell" (ibid., 99), humans may find something reminiscent of what we experience in ourselves, albeit to a very small degree. ${ }^{16}$ Take notice too of the expression "continuous graduation": Jonas indicates a view on purposive action and inwardness as distinguishable in degrees, and that the degrees decrease the farther away from human beings one gets. That is to say, an organism is a purposively acting subject to the degree that it is similar to a human subject.

Is this positive extension of "inwardness" and purposiveness from human beings to the rest of living nature a case of anthropomorphism? At least it may seem to reveal a problematic tendency in Jonas' philosophy for seeing humans as the prototype of purposive being, so that purposiveness in other organisms is understood in "degrees" relative to the human standard. If that is the case, this is a shortcoming of Jonas' view. We will return to this issue below (Section 6).

Apart from Jonas' positive argument from evolution outlined just now, we have hitherto only considered his negative claims - aimed not at establishing that there is immanent teleology in nonhuman organisms, but rather at questioning the grounds for rejecting such a claim. While this strategy is apt for motivating the possibility of natural purpose, we are now in need of a more substantial way of making sense of how teleology is actualized in the natural world. Thus, we move to one of Jonas' core arguments for natural purpose: his analysis of metabolism.

\section{Metabolism}

Most readers of Jonas agree that metabolism is the pivotal concept in his philosophy of organism, and it has been understood as central in his extension of inwardness and purposiveness to nonhuman beings. Metabolism denotes the organism's continuous exchange of matter with its surroundings. This continuous throughput of matter and energy renews tissue and keeps the organs and vital processes going. This peculiar mode of being is common to all organisms, but does not take place in lifeless things. ${ }^{17}$ Hence, at a basic level, there is a common way of organizing matter

\footnotetext{
${ }^{16}$ Here we find Jonas' expression of the Strong Mind-Life Continuity Thesis, a core idea of enactivism (Thompson, 2007: 128). Regarding the co-manifestation of purposiveness, inwardness, and organic life, he writes: "there is no organism without teleology; there is no teleology without inwardness" (Jonas, 1966: 91) and "[w]here else than in the beginning of life can the beginning of inwardness be placed?" (ibid., 58). While these and other formulations suggest that Jonas sees life, purposiveness, and inwardness as strictly codependent, other formulations seem to indicate the possibility of purposiveness beyond subjectivity and inwardness (ibid., 2, 4). We will leave it open here whether Jonas allows for purposiveness in non-subjective, over-individual beings (such as species, ecosystems, the biosphere or being in general).

17 Our claim concerns the metabolic mode of being. Nonliving dissipative structures such as tornados and candle flames also keep their form through a throughput of matter and energy. According to Di Paolo et al. (2017: 127), it is still an open question whether such structures should be considered self-maintaining individuals in a way that displays the basic "Kantian" form of teleology mentioned in the introduction. However, in contrast to metabolic systems, "nothing so far indicates that these [nonliving dissipa-
} 
in all organisms. They have a common physical constitution, or to be more specific, a common physical processual dynamic. Jonas' way of extracting a description of the self-organizational, autonomous features common to all life and making it "the core of the organism's ontology" is, in the words of Weber and Varela, "where his analysis joins directly with the autopoiesis approach" (Weber \& Varela, 2002: 112). Moreover, Weber and Varela follow Jonas' lead in giving metabolism/autopoiesis an existential interpretation in terms of freedom, identity, and purpose, which is considered the first decisive sign of enactivism's "Jonasian turn." 18

Jonas' interpretation of metabolism leads him to claim that there is a specific ontological principle of identity at work in organisms: In organic beings, identity is linked to the dynamic form that maintains itself through metabolism (Jonas, 1966: 76-83). The form is a principle of organization, an eidos, that continuously actualizes itself in new matter and energy. Jonas draws a line between this organic identity and the identity of a stone or a drop of water. Such lifeless things can be analyzed as aggregates, reducible to the immediate identities of the parts. It may be that an atomistic figure of thought is adequate when dealing with lifeless things: They appear to be nothing more than the sum of their parts, and their parts are self-sufficient and independent of the whole they (temporarily) are parts of, as well as of relations to other parts. The identity of a lifeless thing, therefore, may be nothing but the sameness of its material parts over time. ${ }^{19}$ "Organic identity, however, must be of a different nature altogether" (ibid., 82). In organisms, the whole is something other than a mere aggregate. It is concrete and actual unity in a manifold. The wholeness is an "active performance" or achievement. "This active self-integration of life alone gives substance to the term "individual"' (ibid., 79). An organism achieves concrete individuality by its own activity. Its individuality is not a mere projection from a human spectator, nor a construct; the concept of the individual organism is "ontological," not merely "phenomenological" (ibid.). Hence Jonas interprets metabolism as a sign of some sort of action or performance. At every moment in time, the organism, in exchange with its environment, is both the producer and the product of its own continuous activity, and the organism is this purposive process or activity.

While we cannot go into all the details of his analysis of metabolism here, ${ }^{20}$ it is important for our purposes to notice that Jonas considers metabolism a marker of active striving. Organisms are concerned, he claims, with a nod to his former

\footnotetext{
Footnote 17 (continued)

tive] systems have the capacity to adaptively regulate their interactions with the environment" (ibid.), which is Di Paolo's (2005) suggestion for a capacity that would ground the second, sense-making form of teleology in a notion of natural organization.

18 Maturana and Varela's (1980) original theory on autopoiesis, though placing the emphasis on metabolic identity as a definition of life in common with Jonas, was explicitly non-teleological. See Barrett (2017) for an outline of the development of what he calls the "normative turn" in enactivism.

19 Some of Jonas' formulations regarding lifeless things seem to presuppose a classic, mechanistic view of physics, and a view of biology as essentially an application of this view onto living beings. This is most evident in Organism and Freedom (Jonas, 2016: 1-5, 45-58).

${ }^{20}$ See Hverven 2020 for an extended elaboration of this interpretation of Jonas' analysis of metabolism.
} 
teacher Martin Heidegger and the concept of Sorge. ${ }^{21}$ However, in Jonas' philosophy, it is not just Dasein - humans - that are concerned with their own being; all organic beings are concerned with this (ibid., 84, 86). Their very activity and striving to be alive shows that life matters to them. ${ }^{22}$

From this concern (or striving), it follows that the mechanistic pattern of explanation, "the external linear time-pattern of antecedent and sequent, involving the causal dominance of the past, is inadequate" (ibid., 86). For active organic wholes, the future, not the past, is the dominant time horizon: "life is essentially what it is going to be and just becoming" (ibid.). Accordingly, organisms cannot only be understood as products of efficient causes. They must also be understood teleologically, as striving towards future being. Organisms have a telos of their own, which is not an end state; the telos is rather the ongoing processual form itself. The telos - end - of the organism is never fully achieved, once and for all, as a static end station (in that case, death would be the purpose of life). The telos is rather the maintenance of a contingent process that must be re-actualized repeatedly, always with the possibility of failing. Therefore, finitude and vulnerability are essential characteristics of organic life. ${ }^{23}$

\section{Critique of Jonas' argument from metabolism}

The characteristics above raise one big question: What is the basis for this interpretation of metabolism? Critics of Jonas (Barbaras, 2010: 94; Villalobos \& Ward, 2016; Yolton, 1967) read the analysis of metabolism in The Phenomenon of Life as resting on a dubious premise: that life first of all is identified in the mere external process of metabolism. Then action, teleology, sensitiveness, concernedness - in short, "inwardness" - are somehow found in this external process. Accordingly, the critique goes, it is an anthropomorphic "theory of projection": Based on our own inner experience of being acting, living individuals, we have "inside knowledge" and hence we can "interpolate" from the mere external evidence of metabolism to the internal, experiencing life of an organism (Barbaras, 2010). ${ }^{24}$ Thus, we humans, who know purposiveness and inwardness from within, project these qualities onto extended metabolizing entities and take inwardness and purposiveness to be at work in them, as in ourselves. However, as Renaud Barbaras points out, "Nothing in the

\footnotetext{
21 While "concern" for many might be associated with a state of conscious awareness, this is not necessarily the case here. Rather, in the existentialist tradition Jonas is trained in, it connotes a form of practical engagement that usually is pre-reflective and not present in awareness.

${ }^{22}$ It is this step, from metabolic self-production (where the system is the purpose of its own activity) to concern, which Di Paolo (2005) argues lacks the notion of adaptivity in order to be coherent.

23 This does not mean that finitude and vulnerability need to be exclusive to organisms. But in our opinion, it seems reasonable to say that the finitude and vulnerability of organisms stand out - in contrast to nonliving entities - because they matter to the structure itself qua a self-concerned system. See Froese (2017) for an articulation of the significance of precariousness and death in the enactivist case against computationalism about mind and life.

24 De Jesus (2015) argues along the same lines, with reference to Barbaras.
} 
domain of exteriority justifies such an interpolation" (2010: 94). As we understand Barbaras, he uses "exteriority" as a synonym for the Cartesian res extensa - nature conceived as purely mechanical, quantitative, non-subjective substance. ${ }^{25}$ Hence, Barbaras seems quite right in claiming that mere "exteriority" is not "inward," not mental, not purposive. By definition, it is lifeless and cannot express life. In such an interpretation of Jonas, his position depends on a dualism between extendedness and "inwardness." In Barbaras' words, Jonas maintains "the split between interiority and exteriority (...) and that is a consequence of a resolutely materialist ontology. Life is identified first of all in the domain of exteriority, via the concept of metabolism" (ibid.). ${ }^{26}$

If Barbaras' interpretation and critique of Jonas is correct, it would be devastating for Jonas' account of life. Jonas labels his own position "integral monism" (Jonas, 1966: 19), and develops it precisely in contrast to and through critique of reductive materialism and dualism. He explicitly states that the two sides of Cartesian dualism, res cogitans and res extensa, are abstractions (ibid., 22). ${ }^{27}$ And a philosophy of organism "must move beyond these partial abstractions ('body' and 'soul', 'extension' and 'thought', and the like) toward the hidden ground of their unity" (ibid., 19) ${ }^{28}$ On this basis, Jonas seeks to establish an alternative to both materialism and idealism, which he conceives of as abstract and one-sided heirs to the unmediated and equally abstract Cartesian dualism (ibid., 1-26). Moreover, Jonas' critique has a strong normative motivation, since he conceives of modern dualism and materialism as incurably nihilistic. This is a criticism he famously directs at Heidegger's existentialism (ibid., 232). Accordingly, if Jonas' ontology of nature, as his critics claim, is materialistic and/or dualistic after all, he lands on an ontology he himself criticizes as abstract, nihilistic, and unable to understand life. ${ }^{29}$

Barbaras' interpretation of Jonas is, however, misguided at some key points. ${ }^{30}$ First, virtually the same objection Barbaras raises against Jonas is formulated by

\footnotetext{
${ }^{25}$ The term "exteriority" is to our knowledge never used by Jonas. His words are "extended(ness)," "extension," "extensity," and simply "extended (being/substance)," and in The Phenomenon of Life, it is clear that all these terms are used in elaborations of Cartesian res extensa (Jonas, 1966: 290).

26 Sandra B. Lubarsky criticizes Jonas in a similar manner, for occasionally falling back into "psychophysical dualism" (Lubarsky, 2010: 403).

27 There may be a tension here, since (as mentioned in footnote 19) Jonas does not always seem to consider extended substance as an abstraction. Sometimes he seems to accept the concept of pure extended matter as necessary to account for lifeless things such as stones, e.g. when he defines life as form in contrast to the lifeless matter (Jonas, 1966: 80-81), and when he argues against what he takes to be panpsychism in Whitehead (ibid., 95-96). Other times he concedes that matter must, at a minimum, be endowed with a "genuine potency" of becoming alive, and he mentions "a tendency in the depth of being towards (...) freedom" (ibid., 2, 4), which means, among other things, that matter cannot be defined properly without reference to life. In our interpretation, we put the most emphasis on these formulations, where pure extended matter is understood as an abstraction in all circumstances. This makes Jonas' account more coherent.

28 This is a clear parallel to Merleau-Ponty's call to conceive of the body as "a third genre of being between the pure subject and the object" (2012: 366).

29 Cf. Jonas' sharp examination of the familiarity between dualism, materialism, and idealism (Jonas, 1966: 17-19).

30 See also Section 5.3.
} 
Jonas himself, when he writes that "no mere analysis of the physical record [i.e. extended matter] will ever yield" internal identity (ibid., 82). Moreover, Jonas' examination of metabolism, in the essay "Is God a Mathematician?", certainly starts with a mere spectator perspective ("the Divine Mathematician") that sees nature as res extensa. But his aim is precisely to show that this perspective leaves out something decisive and hence is abstract. Jonas asks the reader to imagine a god who created the world as mere extended being and only knew of the world as such extensity. Would such a god understand the phenomenon of life? No, this god "misses the decisive point - the point of life itself: its being self-centered individuality" (ibid., 79). The mathematical description does not capture life as experienced or lived. We humans ("poor mortals"), however, experience this dimension of being. Hence, in Jonas' thought experiment, we know parts of the world unconceivable to this god; for example, we know of sight as an experience, not merely as an extended physicochemical process. The imagined god would be ignorant of this quality of sight, so evident to us, and such an ignorant god must be rejected: There is no "Divine Mathematician."

Accordingly, in Jonas' view, a more comprehensive account of being and the phenomenon of life must recognize that the purely quantitative, mathematical perspective is limited and abstract. The shortcomings of the mathematical perspective provide motivation for reviving and grant validity to the more concrete bodily perspective; "life can be known only by life" (ibid., 91) as Jonas famously puts it. It is, however, still unclear what this amounts to - does "life" know itself primarily through introspection, or through encounters with other living beings? - but at least we now know that to accept the validity of a bodily perspective entails rejecting the picture of nature as mere extended substance. The central turning point of "Is God a Mathematician?" thus shows that the approach Jonas recommends is to return to bodily experience and survey what aspects of that perspective materialism has omitted in its process of abstraction. In this way, pace Barbaras, Jonas does not first identify life "in the domain of exteriority." Rather, his conclusion is negative: Life cannot be identified in the domain of pure extension.

Accordingly, Jonas does not merely accept the concept of purely extensive metabolism at face value, as expressing what life really is. Rather, he reinterprets the concept as a descriptive generalization covering different concrete experiences of aliveness. On its own, in abstraction, metabolism does not express what life is. But it can be interpreted as a sort of "gesture" towards those bodies where life is expressed, and experienced, as concrete. This puts Jonas in the position to give what he calls "an 'existential' interpretation of biological facts" (ibid., xxiii). ${ }^{31}$

To sum up, in his discussion of "the Divine Mathematician," Jonas reveals the shortcomings of the objectivist "view from nowhere" (Nagel, 1986) when it comes

\footnotetext{
31 Jonas claims that this interpretation of biological concepts is also unknowingly made by convinced materialist biologists: "Else they would altogether miss the existence of life around them and thus have no object for inquiry - the concrete from which to make their abstractions - to begin with" (Jonas, 1966: 91). This can be read as an explicit contradiction of Barbaras' critique that Jonas maintains "the split between interiority and exteriority (...) and that is a consequence of a resolutely materialist ontology. Life is identified first of all in the domain of exteriority" (Barbaras, 2010: 94).
} 
to grasping the reality of life, arguing instead that that achievement comes from the engaged, bodily perspective of our primordial experiences and encounters. Does that mean that we now have a fully satisfying account of how we humans are able to understand nonhuman organisms as acting purposively? We do not think so. At this point, much depends on what is to be found in concrete experiences and encounters, which is the topic of the fifth and last step of Jonas' philosophy that we will consider.

\section{Encounter and otherness}

\subsection{The element of encounter}

A central yet often overlooked claim by Jonas is that encounters enable a specific world relation with epistemological significance. To understand what this means, it is helpful to notice a point Jonas makes early in The Phenomenon of Life, in his "Note on anthropomorphism." There he remarks that a Cartesian split between subjective human being and extended nature has led to the predominance of one specific world relation with an epistemological bias. He writes that in modern thinking, an "epistemological monopoly" is

accorded to the perceptual mode of cognition, i.e., to outside knowledge mainly in the visible mode, in consequence of which "objectivity" becomes essentially the elaboration of exterior sense-data in the lines of their extensional properties. Other possible modes of relation to reality, such as the communication between life and life, or the experience of the impact and resistance of things in bodily effort, fell short of the ideal of exact knowledge and ceased to count. (Jonas, 1966: 35, our emphasis)

Here, Jonas makes a distinction between three modes of world relation, each providing a specific kind of knowledge: 1) The relation between detached subject and extended object, 2) communication between life and life, and 3) the experience of the resistance of things in bodily effort. ${ }^{32}$ Later in the book, Jonas introduces the concept of "the element of encounter" in perception. Against the backdrop of the tripart distinction between world relations, this concept can be understood as an elaboration of 2) and 3). Jonas here defines it as "the self-communication of the object to my receptivity and its insistence on itself even while in my perceptive hold" (1966: 168). Such encountered otherness - a foreign solidity or relative independence - is necessary for judging anything as real at all. To perception, "the felt affectiveness

\footnotetext{
32 Barbaras (2010) seems to (mis)interpret Jonas as only basing his analysis of metabolism on the first kind of world relation with its epistemological limitations. That we constantly engage in other, more basic forms of relations to the world - especially to other humans and living creatures - is also a key enactivist point. See e.g. Colombetti (2014), Fuchs and De Jaegher (2009), Gallagher (2020), and Thompson (2007, ch. 13).
} 
of the data [...] is necessary for the experience of the "reality' of the real" (ibid.). Hence, Jonas' claim is that realism rests on this "element of encounter."

These general claims also apply to the specific case of nonhuman organisms. Experience of the reality of nonhuman others (and human others, for that matter) depends on encounters with these others, in which their "insistence on themselves" as purposive, living beings is "affectively felt" 33 by the experiencing subject. If Jonas is to be coherent, this is the experiential basis a theory of organism requires. ${ }^{34}$

But Jonas' statements about the embodied perspective in "Is God a Mathematician?" are too general and undifferentiated to meet this requirement. There, he does not sufficiently explain how the embodied human is able to recognize and be affected by life and purpose in concrete others. Therefore, it still does not account fully for the experiential basis for the strong claims made by Jonas in his interpretation of biological concepts. As presented until now, Jonas' position may still be accused of projection and anthropomorphism - not because it is materialist, but because it is too egocentric. To respond properly to criticisms of anthropomorphism, it is necessary to elaborate on our embodied experience and explicitly incorporate into it encounters with and relations to others. To understand others as active and purposive, an account of how experiences with such others is an emphatic experience (Bernstein, 2001: 302), ${ }^{35}$ inseparable from our understanding of ourselves and our world, is needed. Only on such a basis can an "existential" approach to life be fully appreciated. What does Jonas have to offer here?

\subsection{The life experience in encounters}

In The Phenomenon of Life, the best formulations Jonas offers on the experience of life in others are given on the first page of the first essay, in his description of the experiential basis for early days animism or "panvitalism": "That the world is alive is really the most natural view, and largely supported by prima-facie evidence. On the terrestrial scene, in which experience is reared and contained, life abounds and occupies the whole foreground exposed to man's immediate view" (Jonas, 1966: 7). Jonas refers to this as "the life experience" (ibid., 15): Life is experienced as there, in the terrestrial world. Later, Jonas claims, this experience was suppressed by a worldview based on the opposite experience, "the death experience": Life is absent there, e.g. in that dead body or in that stone. In generalized and reified form, this experience leads to what Jonas names the "ontology of death" of modernity, which equals the materialism discussed above (ibid., 9-12).

However, when Jonas later in the book argues that there are basic experiences that a fully materialist worldview cannot account for, he does not refer to "the life

\footnotetext{
33 On our reading, this can be seen as a precursor to Thompson's view on "empathy" between living beings, in Mind in Life (2007: 165, 382-412).

34 In accordance with Bernstein (2001: 301-305) argues that the experience of the difference between living and nonliving beings is emphatic - especially forceful and clear - through a reading of Wittgenstein.

35 See previous note.
} 
experience." He does not point to the fact that we experience life as there, in others different from but similar to our own embodied selves. Rather, he points to the fact that we experience life as present here, in me, in my body (ibid., 79). Hence, the experiential basis drawn upon here for the interpretation of metabolism is the experience of life in me, not you; here, not there; in the self, not the other. There is thus a danger that ontology collapses into egology, because the "element of encounter" necessary for realism about others is absent. ${ }^{36}$

Admittedly, it is difficult to say precisely what Jonas' position is at this point. Notice the ambiguities in this quote:

[I]nternal identity is implicit in the adventure of [metabolic, processual] form and is spontaneously assumed on its external, morphological evidence which alone is open to inspection. But what kind of inference is this? And by whom? How can the unprepared observer infer what no mere analysis of the physical record will ever yield? [...] The observer of life must be prepared by life. In other words, organic existence with its own experience is required of himself for his being able to make that inference, which he does make all the time, and this is the advantage - perennially disowned or slandered in the history of epistemology - of our "having", that is, being, bodies. [...] It is by this interpolation of an internal identity alone that the mere morphological (and as such meaningless) fact of metabolic continuity is comprehended as an incessant act (...). (Jonas, 1966: 82)

We assume that this paragraph is a source of dualistic interpretations of Jonas, claiming that his account presupposes that humans mysteriously find "inwardness" and purposiveness in mere "external, morphological evidence." In such an interpretation, the passage serves to prove that Jonas' position is at once both materialistic and "spiritualistic" (Barbaras, 2010: 121), because we simply detect, or "interpolate" from our own experience, a "spirit" in the "machine." Seen in isolation, this is a possible interpretation of the quoted paragraph. But based on the sources we have presented above, it can also be read otherwise. It can be read as saying that the recognition of other beings as acting, real wholes is primordial in our experience, prior to the scientific view of organisms as extended matter; and that the experience of the morphological evidence of other living beings for us is expressive and meaningful, something that can be understood and interpreted, and that this is more basic than the view of them as mere extended matter. This could be the meaning of Jonas' above-quoted statements that the recognition of "internal identity" and meaningful action in organisms is something we, humans, "spontaneously assume" and that it is an inference "we make all the time."

The clash between these two opposing interpretations is difficult to settle based on The Phenomenon of Life alone. What is missing there is an examination of how this "spontaneous inference" takes place in encounters with nonhuman others. Jonas

\footnotetext{
${ }^{36}$ Our use of the Levinasian term "egology" is indebted to Robert R. William's use of it in his critique of Husserl: "Husserl did not go far enough when he developed phenomenology as an egology without ontology" (Williams, 1992: 95).
} 
could have made his position clearer by drawing on "the life experience" as well as his insights regarding encounter and realism in his interpretation of metabolism, but he does not. What is missing in The Phenomenon of Life, which would have made it harder to accuse him of anthropomorphism, is an explicit statement of the fact that we recognize signs of life in concrete living others, not, at first, through introspection of our own inwardness, projected on the more generalized concept of "metabolism." As we will see below, Jonas' works contain the resources for arguing that it is rather in the concrete movements, gestures, or growth of other bodies that we primarily recognize the expressions of life. In general terms, what is underdeveloped in The Phenomenon of Life is a philosophy of encounter and otherness. Such an examination is, in our view, necessary for Jonas' view of organisms, and its absence is a weakness that makes his account of the phenomenon of life unstable.

This instability probably explains, and perhaps even justifies, some of the skepticism towards the Jonasian influence on the enactivist field. For, rather than clarifying and sorting out this ambiguity in Jonas' account, some of the most central enactivist literature on Jonas tends to reproduce it. In Weber \& Varela, for instance, we find the claim that "[i]t is actually by experience of our teleology - our wish to exist further on as a subject, not our imputation of purposes on objects - that teleology becomes a real rather than an intellectual principle" (2002: 110). And in Mind in Life, Thompson states that "this inwardness or interiority [and consequently, purposiveness] is disclosable to us because we ourselves are living beings who experience our own bodily selfhood firsthand" (2007: 163). We are not saying that there is no truth in these statements. After all, we established in the previous section that our concrete, bodily perspective is essential for the ability to grasp the purposive reality of other organisms. What is problematic is the suggestion that this grasping is the conclusion of a process that unequivocally starts with introspective evidence of life in ourselves; this is precisely what opens the door to accusations of anthropomorphism and projection. However, rather than this being a reason for closing the door to Jonasian influences on the enactivist project, we think that a more thorough reading of Jonas' works proves that he in fact has resources that can be of use in resolving this ambiguity, which to some degree still haunts enactivism.

\subsection{Recognition of life in others, prior to introspection}

In "Change and Permanence," originally published in 1969, Jonas makes it clear that he does not regard "inwardness" as something human subjects have unmediated introspective access to. On the contrary, he stresses the irreducible intersubjectivity of human self-knowledge:

Neither the knowledge of other minds, nor even the knowledge of mind as such, originates from the inspection of our own. On the contrary, already the knowledge of our own mind, even our having one in the first place, is a function of acquaintance with other minds. Knowledge of inwardness as such, whether one's own or that of others, is based on communication with a whole human environment which determines, certainly codetermines decisively, even what will be found in eventual introspection. [...] An understanding of 
the inwardness of others, in advance of and beyond what "introspection" could have found in one's own inwardness, is a precondition for the very emergence of such an inwardness. (Jonas, 2010: 246-247)

It is hard to imagine a clearer statement on the mediatedness of human "inwardness." ${ }^{37}$ In the above paragraph, Jonas strongly opposes a view on human inwardness as something directly accessible. His view seems to be consistent with Hegelian recognition theory on this point: Having a mind - or a "self" as recognition theorists usually say (there may be a difference here) - is a dialectical achievement. It is acquired only through some sort of relation or confrontation with otherness. To develop a human mind, this "otherness" must also be encountered in distinctly human others, capable of recognizing the human self as human. Only through being recognized as a human self by other human selves (which one must recognize in return) does one achieve a human self. ${ }^{38}$

If this is Jonas' view on the human self, it is worth noting. Barbaras (2010) and others criticizing Jonas for a "theory of projection" seem to interpret him in exactly the opposite way, as claiming that human "inwardness" is accessed directly through introspection and then projected onto others. But here Jonas is evidently arguing the opposite, namely that relations to and recognition of others are necessary preconditions for all introspection. He is crystal clear in his rejection of a theory of projection, stating that we have knowledge of other minds "not by analogical inference, overt or covert, from myself to others; not by transference and projection, as the post-Cartesian doctrine of consciousness made it almost de rigueur to hold" (Jonas, 2010: 246).

At this point, it is fair to voice the following objection: Have we not fallen back into anthropocentrism? That is, are not the "others" in question here only human others, meaning that the inwardness of nonhuman organisms could still be conceived as the result of a human projection? In fact, in the same essay, Jonas continues to elaborate on the question of knowledge of other minds in an explicitly non-anthropocentric way. He claims that animals also seem to recognize life in others: "The recognition of other life is a fundamental feature of the outside relation integral to the animal organism. Among the objects of perception, neutrally classed as 'things,' living things as living are paramount" (ibid., 248). This recognition of life by life goes across species: "A creature recognizes greed or aggression when it meets it in a fellow creature's eyes (or in posture, sound and smell), and this far beyond its own kind" (ibid.). How could it be that life is recognized in others? Jonas answers: "Animal life is expressive, even eager for expression. It displays itself; it has its sign codes, its language; it communicates itself" (ibid., orig. emphasis). Recall that Jonas considered the "self-communication" of the object in concrete encounters to be a criterion for realism. Hence, Jonas here gives the statement missing in The

\footnotetext{
37 That our human form of inwardness, as well as our access to and knowledge of our own inwardness as such, is enabled and mediated by intersubjective practices is a claim frequently advocated in enactivist literature. See e.g. Thompson (2007), De Jaegher and Froese (2009), and Gallagher (2020).

38 See e.g. Honneth (1992), Williams (1997), and Pippin (2008).
} 
Phenomenon of Life: Nonhuman animals self-communicate - insist on themselves as living - and are expressive.

Notice that Jonas' formulations here are limited to animal life. Hence, we do not yet have a Jonasian defense of the deep mind-life continuity thesis, which ascribes a form of inwardness to all forms of life. Is this something he can provide?

\subsection{Encounter in Organism and Freedom}

More than a decade before the publication of The Phenomenon of Life, Jonas had already formulated a more systematic and worked-through monograph, titled Organism and Freedom. Following rejections from a couple of publishers, he reworked and published parts of the book as the essays in The Phenomenon of Life, until recently known as the most fully articulated formulation of his philosophy of biology. In 2016, Organism and Freedom was published as a part of the collected works of Hans Jonas. In this original manuscript, Jonas mentions exactly what we miss in the more fragmented The Phenomenon of Life, namely, concrete encounters with nonhuman others. Consider the following passage, which clearly illuminates the expressive nature of life:

When in doubt whether the victim of an accident is alive or dead, we look to see whether or not he breathes, whether or not his heart beats, and the like. When in doubt whether a lizard by the roadside is alive or dead, we may tickle it with a grass-stalk and see whether it responds, i.e., moves. To ascertain whether a sapling we have planted has kept alive, we observe it over a number of days and see whether it grows. (Jonas, 2016: 2, ch. II)

These few sentences alone give more information about concrete encounters with living others - both human and nonhuman - than the whole of The Phenomenon of Life. Importantly, Jonas here includes non-animal organisms, represented by the sapling. In this passage, the human "we" recognizes life in certain movements, such as breath, pulse, growth, or locomotion. And these movements are not merely perceived as mechanical; rather, they appear as expressions of actions: "We expect of living things that they do something" (ibid., orig. emphasis). Either in their aliveness or in their lifelessness, the victim, the lizard, and the sapling satisfy Jonas' criteria for "the element of encounter" (Jonas, 1966: 168); they "insist on themselves," they "self-communicate" to our receptivity, hence they are real, either as living or as dead. ${ }^{39}$ Organic beings' "insistence on [themselves] even while in my perceptive hold" (ibid.) could perhaps take the form of the gaze of a wild bird or an elk, or the stubborn resistance of a cockroach, or the twitch of a cod on the hook.

However, what is the difference between this "insistence" and the "insistence" of lifeless things "in my perceptive hold"? Is not the desk in front of me also quite insistent? That is, I could close my eyes, try to think it away, then open them, and it

\footnotetext{
39 We see an affinity here with the enactive concept of empathy, understood as a kind of embodied recognition of others as alive and mindful. See e.g. Thompson (2007: ch. 13), Colombetti (2014), and Gallagher (2020).
} 
will be there, nevertheless. It is not clear what Jonas would answer, but as we understand him, it seems reasonable to claim, on his behalf, that only life insists on itself, in the sense that self-concern is expressed by its behavior. It is of course possible for us to err in distinguishing life from nonlife. Just because something immediately appears as if it were insisting on itself, this does not mean that it actually is selfinsisting - this is usually quite easily discovered by further scrutiny of the entity in question, as Jonas demonstrates in the paragraph quoted above. ${ }^{40}$

To elaborate on what we see in living others, we could say in general terms that it is likeness. According to Jonas' own position on human perception and "image-making," to perceive likeness means to see neither identity nor non-identity, or rather to see both aspects at once (Jonas, 1966: 158-167). The sapling grows like I did as a child, but it is also very different from me. The lizard moves away, so can I, and in that respect the lizard is more like me than the sapling, but we are still very different. The victim of the accident may speak to me, and hence there is another level of similarity, but still we are different. His body is not mine; I do not experience his pains the way he does; his whole life history is different from mine, etc.

In Organism and Freedom, Jonas describes these concrete encounters before the concept of metabolism as externality is introduced. This fact challenges critics of Jonas (e.g. Barbaras) who accuse him of beginning with a "mere exteriority" view of organisms and then superimposing life on this extended form. Rather, Jonas begins his more systematic examination in Organism and Freedom with the experience of life being already there in living others, not in need of being animated by a human projection. That fact fits our interpretation of his view, which says that the experience of other organisms as living and acting is primary to the view of them as extended matter. ${ }^{41}$

At this point, Jonas' argument for how we are justified in conceiving of the purposive activity of other living beings can be reconstructed as follows: Because we humans, at a basic bodily level, recognize either life or nonlife in other beings, we are in a position to be able to let this "life experience" - experience of life in others

\footnotetext{
${ }^{40}$ However, that does not mean that Jonas avoids the possibility of error, or skepticism, but in our view this is not devastating to his position. In our reading, Jonas places great emphasis on concrete encounters with others as a precondition for the recognition of life. Such a view does not pretend to do away with all skepticism, or avoid any possibility of error. Neither does it pretend to reach total unambiguity. Because the (encounter with) other is considered as an inevitable source for the knowledge in question (knowledge of other minds), the epistemic subject must refrain from complete epistemic control or security.

41 It must be noted that Jonas some pages later interprets the lizard encounter in a way that is problematic for our interpretation: "We observe the lizard's motions upon our touching of it, but not its sensing the touch or its consequent excitement. Sensing and excitement we witness in ourselves 'from within', and this is how we know about them, while other living beings we witness only in their externalization on motions or other changes of the body" (Jonas, 2016: 5, ch. 2). These formulations show that the critique of Jonas as relying too much on a dualist distinction between the "internal" and the "external" does have textual support. As Lubarsky (2010) correctly observes, Jonas occasionally falls back into psychophysical dualism. We do not deny that Jonas' position is ambiguous at this point, but as interpreters of Jonas we think one gets to the point where one must choose what to put the most emphasis on: certain dualistic formulations or the resources Jonas offers to overcome dualism.
} 
in encounters - inform our understanding of the scientific concept of metabolism. ${ }^{42}$ Metabolism becomes, in Jonas' philosophy, the abstract minimal requirement for bodily similarity in otherness that delimits and gestures towards those "others" who are able to recognize purposively acting others in concrete encounters.

\section{Identity-thinking: The danger of reducing the other to the self}

Even though this correction shows that Jonas' texts contain resources for rejecting the most devastating points in the critiques of "the Jonasian turn," we still find Jonas' interpretation of metabolism partly dissatisfactory. Our reason is the following: Jonas' account of nonhuman organisms does not seem to live up to his insights on "likeness," mentioned above, because he tends to grant living creatures purposive action and subjectivity only to the degree that they are identical to the human body or self.

This claim may seem unfair, since Jonas does give an account of difference between sorts of organisms. In The Phenomenon of Life, he pictures a hierarchy of different degrees of "needful freedom" exercised by living beings. ${ }^{43}$ The freedom entails a relative detachment and independence of particular matter (Jonas, 1966: 80-81). All metabolic structures have some freedom, according to Jonas, due to the way in which they maintain their identity through material exchange and renewal. In his view, freedom is a function of mediation between the living form and particular matter. Metabolism itself is a basic form of mediation (ibid., 183). Further, Jonas differentiates between plants and animals, the latter having emotions and the abilities of locomotion and perception (ibid., ch. 4), and between animals and humans, the latter being able to abstract and make images and symbols (ibid., ch. 7). Jonas interprets these different abilities as signs of different degrees of dialectical mediations between an organism and its surroundings and the specific matter it is made of at a particular point in time. Greater distance and complexity of mediation in turn equal greater freedom, although all freedom remains "needful" in the sense that it must be exercised by a living form that has to be realized in some matter.

\footnotetext{
42 In Organism and Freedom, Jonas claims that active movement is not the only evidence of life that springs forth from concrete encounters with others. He writes that we cannot "commit ourselves to an enquiry on terms of activity [i.e. metabolism] alone" (Jonas, 2016: 3, ch. II). Equally important is that we observe and expect that living beings display reactions ("responsive behavior"). This is most evident in the example with the lizard, which is recognized as living when it responds (by moving) to being tickled. Jonas writes in Organism and Freedom that the mere process of metabolism "cannot even be meaningfully described" without an account of some "sensitivity" or "irritability," which are rudimentary forms of "sentience" and "perception." Accordingly, it would be most accurate to add "irritability" in the formulations in this paragraph, but we limit ourselves to "metabolism" for the sake of space.

43 For an enactivist use of Jonas' notion of needful freedom, see Di Paolo (2009: 16 ff.). It is drawn on here, together with Jonas' idea of "transitions" between different forms of life, to give an enactive account of the differences in organizational identity between kinds of organisms (e.g. how animals are distinguished from other life forms) as well as of how autopoiesis underlies but does not fully determine every organism's form of life.
} 
However, although Jonas' concept of dialectical, needful freedom is thought-provoking and deserves more attention, it does not really account for nonhuman difference. All the mediating traits Jonas mentions - metabolism, emotions, locomotion, image-making etc. - are exercised by humans. Moreover, they are analyzed by Jonas as most completely represented in human beings, and only to lesser degrees in nonhuman others. Hence, no mediation or freedom can be genuinely different from human freedom, only the same to a lesser extent. This lack of appreciation of nonhuman difference is probably clearest in the following statement by Jonas:

Perhaps, rightly understood, man is after all the measure of all things - not indeed through the legislation of his reason but through the exemplar of his psychophysical totality which represents the maximum of concrete ontological completeness known to us: a completeness from which, reductively, the species of being may have to be determined by way of progressive ontological subtraction down to the minimum of bare elementary matter (...). (1966: 23-24)

Here Jonas claims that nonhuman organisms and nature in general are known to us not in their rich difference, but as human beings minus something. Crudely put, Jonas seems to claim that if you begin with a human being and subtract some complexity, you have an animal. Subtract some more and you have a plant. Subtract even more and you have "bare elementary matter."

This account leaves out the possibility of genuine difference, not to mention the possibility that nonhuman freedom may exceed human freedom in any way. This is not satisfying, because one can easily think of organisms with abilities that (probably) give them experiences and freedom that are unavailable to humans. Think of the eagle flying with its own wings. It exercises a freedom that humans can only get a vague idea of through complicated technological aids (i.e. airplanes and hanggliders). In Jonas' account, such a freedom seems to be subsumed under the great label of "locomotion," and hence reduced to something equal to human walking and running. But it is not - it is different.

We cannot see that Jonas appreciates such differences. Hence, Jonas' recognition of nonhuman life may be accused of what Theodor W. Adorno calls "identity-thinking" (2003 [1966]), which seeks to gain knowledge about something by identifying it with something already known. Identity-thinking subsumes "individuality (sensuous particularity) under a coherent, unifying, simplifying, explanatory universal (myth, god, natural law, unified science)" (Bernstein, 2001: 30).

In Jonas' case, as mentioned above (Section 3), nonhuman others are known as "others" or individuals only when we, humans, identify degrees of ourselves in them. What justifies this claim? Let's look at Jonas' interpretation of the theory of evolution in more detail: "If man was the relative of animals, then animals were the relatives of man and in degrees bearers of that inwardness of which man, the most advanced of their kin, is conscious of in himself' (Jonas, 1966: 57, our emphasis). Here Jonas claims that animals, and maybe plants, are bearers of a degree of "that inwardness" which man is conscious of in himself. And the "dignity" of nature rests on that identification of self-sameness (or human-sameness) in nonhuman others. This account can be criticized for what environmental ethicists call "moral extentionalism" or "generalized egoism" (Callicott, 1989: 84-85). The two labels 
single out a typical procedure of modern ethical thinking: Moral consideration (and in Jonas' case being, in the specific sense of being alive, with all that follows) is extended to nonhuman others in proportion to their identity with humans.

A problem with such an account of knowledge of others is the danger of reducing the other to the self, of dissolving difference in unity - or, in Adorno's words, the danger of losing sight of "non-identity." 44 Thus, Jonas seems to be guilty of a "denial of difference," similar to what other prominent environmental philosophers, such as Arne Næss, Tom Regan, and Paul Taylor, have also been criticized for (Plumwood, 1993: 165-189).

What Jonas does not do, in the quoted paragraphs, is to let experiences of likeness, the intertwining of identity and non-identity, be the basis for the recognition of nonhuman others. He relies too heavily on identity. Thus, he misses the opportunity to appreciate that the significant being of the other is not wholly transparent to the self, and that the self does not have the sole power to predict, influence, or transform the other, but that the other can also exceed, influence, or transform the self in unexpected ways. ${ }^{45}$ In short, a more detailed analysis of the specific, concrete, living, mediating other as it is perceived in encounters is missing in Jonas' account. ${ }^{46}$

\section{Conclusion}

We have purported to provide a critical overview of Jonas' case for natural purpose through a reconstruction of five arguments from his works. Drawing on sources beyond the most-cited passages from The Phenomenon of Life, we have shown how Jonas' philosophy contains resources both for responding to his critics and for illuminating lesser-known aspects of a problem that is very much alive in the enactivist context. Through our investigation of Jonas' ideas, we have shown how the reality of natural purpose can be motivated from a variety of perspectives: First, how the discovery that the anti-teleological core of much natural science is primarily methodological allows for the possibility of purpose in nature; second, how the performative self-contradiction involved in rejecting the reality of purpose is evidence of the reality of teleology at least in the case of humans; third, how the fact of evolution makes human exceptionalism prima facie implausible; and last, how Jonas makes the positive case for immanent teleology in nonhuman organisms through his existential

\footnotetext{
${ }_{44}$ In this context, this is a problem for the justification of Jonas' view on the purposiveness of individual nonhuman organisms. Further, it leads to a lacking description of organic being in general, because relations between differentiated organisms are left out. Jonas does not mention reproductive (sexual) relations, symbiotic relations, nor relations between parent and offspring (Kass, 1995: 458; Hösle, 2001; Pommier, 2017).

45 Such a view on encounters with nonhuman others is presented by Freya Mathews (Mathews, 2003: 78).

46 Every time the word "otherness" is mentioned in The Phenomenon of Life, it refers to the otherness of the world in general, in dialectical opposition to the organism. This is an important point in itself, but this concept of otherness is not sufficiently differentiated. It does not account for the specific otherness of living others, of organisms.
} 
interpretation of metabolism and how he anchors the "evidence" of nonhuman purposiveness in concrete encounters with living organisms.

Although there is plenty of room for further discussion about the arguments Jonas proposes, and although enactivism has moved beyond Jonas in several respects, we hope to have shown that he still provides insights that are relevant to enactivism. However, we do not claim that Jonas' position is without difficulties. Thus, our final point was that Jonas' account is guilty of a "denial of difference" in nonhuman others, granting them purposiveness only to the extent that human traits can be identified in them. By drawing attention to these challenges faced by Jonas, we hope to have illuminated some possible pitfalls for the enactive account of normativity in nature. We also hope to have shown, pace the critics of the "Jonasian turn," a more nuanced version of Jonas' position. We would even dare to suggest that Jonas' writings on concrete encounters as a non-anthropomorphic ground for ascribing teleology to nonhuman organisms should be further explored by enactivism as a resource for defending against those skeptical of its normative turn.

Funding Open access funding provided by NTNU Norwegian University of Science and Technology (incl St. Olavs Hospital - Trondheim University Hospital).

Open Access This article is licensed under a Creative Commons Attribution 4.0 International License, which permits use, sharing, adaptation, distribution and reproduction in any medium or format, as long as you give appropriate credit to the original author(s) and the source, provide a link to the Creative Commons licence, and indicate if changes were made. The images or other third party material in this article are included in the article's Creative Commons licence, unless indicated otherwise in a credit line to the material. If material is not included in the article's Creative Commons licence and your intended use is not permitted by statutory regulation or exceeds the permitted use, you will need to obtain permission directly from the copyright holder. To view a copy of this licence, visit http://creativecommons.org/licen ses/by/4.0/.

\section{References}

Adorno, T. W. (2003) [1966]. Negative Dialektik, Jargon der Eigentlichkeit. Suhrkamp.

Abramova, K., \& Villalobos, M. (2015). The apparent (ur-)intentionality of living beings and the game of content. Philosophia, 43, 651-668

Barandiaran, X. (2016). Autonomy and enactivism: Towards a theory of sensorimotor autonomous agency. Topoi, 36, 409-430

Barbaras, R. (2010). Life and exteriority: The problem of metabolism. In J. Stewart, O. Gapenne, \& E. A. Di Paolo (Eds.), Enaction: Toward a new paradigm for cognitive science (pp. 89-122). The MIT Press.

Barrett, N. F. (2017). The normative turn in enactive theory: An examination of its roots and implications. Topoi, 36, 431-443

Bernstein, J. M. (2001). Adorno: Disenchantment and ethics. Cambridge University Press.

Callicott, J. B. (1989). In defense of the land ethic: Essays in environmental philosophy. State University of New York Press.

Colombetti, G. (2014). The feeling body: Affective science meets the enactive mind. The MIT Press.

De Jaegher, H., \& Froese, T. (2009). On the role of social interaction in individual agency. Adaptive Behavior, 17(5), 444-460

De Jesus, P. (2015). Autopoietic enactivism, phenomenology and the deep continuity between life and mind. Phenomenology and Cognitive Sciences, 15, 265-289

Di Paolo, E. (2005). Autopoiesis, adaptivity, teleology, agency. Phenomenology and Cognitive Science, 4, $429-452$

Di Paolo, E. (2009). Extended life. Topoi, 28, 9-21 
Di Paolo, E., Buhrmann, T., \& Barandiaran, X. (2017). Sensorimotor life: An enactive proposal. Oxford University Press.

Evernden, N. (1993). The natural alien. University of Toronto Press.

Froese, T. (2017). Life is precious because it is precarious: Individuality, mortality, and the problem of meaning. In G. Dodig-Crnkovic \& R. Giovagnoli (Eds.), Representation and reality in humans, other living organisms and intelligent machines (pp. 33-50). Springer International Publishing.

Fuchs, T., \& De Jaegher, H. (2009). Enactive intersubjectivity: Participatory sense-making and mutual incorporation. Phenomenology and the Cognitive Sciences, 8(4), 465-486

Gallagher, S. (2020). Action and interaction. Oxford University Press.

Griffin, D. R. (1998). Unsnarling the world-knot: Consciousness, freedom, and the mind-body problem. Wipf \& Stock.

Honneth, A. (1992). Kampf um anerkennung: Zur moralischen grammatik sozialer konflikte. Suhrkamp.

Hösle, V. (2001). Ontology and ethics in Hans Jonas. Graduate Faculty Philosophy Journal, 23, 31-50

Hutto, D. D. \& Myin, E. (2013). Radicalizing enactivism: Basic minds without content. The MIT Press.

Hverven, S. (2020) Encounter and otherness: A critical reading of Hans Jonas's Interpretation of Metabolism. In O. Lysaker (Ed.), Between Closeness and evil: A Festschrift for Arne Johan Vetlesen (pp. 89-124). Scandinavian Academic Press.

Jonas, H. (1966). The phenomenon of life: Towards a philosophical biology. Northwestern University Press.

Jonas, H. (2010) [1980]. Change and permanence: On the possibility of understanding history. In Philosophical essays: From ancient creed to technological man (pp. 237- 260). Atropos Press.

Jonas, H. (1984). The imperative of responsibility: In search of an ethic for the technological age. The University of Chicago Press.

Jonas, H. (2016). Organism and freedom. An essay in philosophical biology. Online-appendix zu Band i, 1 der Kritischen Ausgabe der Werke von Hans Jonas. Jens Ole Beckers und Florian Preußger.

Juarrero, A. (1999). Dynamics in action: Intentional behavior as a complex system. The MIT Press.

Kant, I. (2006). 1790. Felix Meiner Verlag.

Kass, L. (1995). Appreciating the phenomenon of life. The Hastings Center Report, 25, 3-12

Kee, H. (2018). Phenomenology and naturalism in autopoietic and radical enactivism: Exploring sense-making and continuity from the top down, Synthese, 1-21.https://doi.org/10.1007/s11229-018-1851-3.

Köhler, W. (1966) [1938]. The place of value in a world of facts. Liveright.

Lubarsky, S. B. (2010). Jonas, Whitehead, and the problem of power. In H. Tirosh-Samuelson \& C. Wiese (Eds.), The legacy of Hans Jonas: Judaism and the phenomenon of life (pp. 397-418). Brill.

Mathews, F. (2003). For the love of matter: A contemporary panpsychism. State University of New York Press.

Maturana, H. R. \& Varela, F. (1980). Autopoiesis and cognition: The realization of the living. D. Reidel Publishing Company.

Merleau-Ponty, M. (1963) [1942]. The Structure of Behavior. Duquesne University Press.

Merleau-Ponty, M. (2012) [1945]. Phenomenology of perception. Routledge.

Nagel, T. (1986). The view from nowhere. Oxford University Press.

Pippin, R. B. (2008). Hegel's practical philosophy: Rational agency as ethical life. Cambridge University Press.

Plumwood, V. (1993). Feminism and the mastery of nature. Routledge.

Pommier, E. (2017). Hans Jonas's philosophical biology: Metaphysics or phenomenology? International Philosophical Quarterly, 57, 453-469

Thompson, E. (2007). Mind in life: Biology, phenomenology, and the sciences of the mind. The Belknap Press of Harvard University Press.

Thompson, E. (2018, January). Review of Evolving enactivism: Basic minds meet content. Notre Dame Philosophical Reviews. Retrieved February 11, 2020, from https://ndpr.nd.edu/news/evolving-enactivismbasic-minds-meet-content/

Varela, F. J., Thompson, E., \& Rosch, E. (1991). The embodied mind. MIT Press.

Villalobos, M., \& Ward, D. (2016). Lived experience and cognitive science: Reappraising enactivism's Jonasian turn. Constructivist Foundations, 11, 204-233

Villalobos, M., \& Palacios, S. (2019). Autopoietic theory, enactivism, and their incommensurable marks of the cognitive. Synthese. https://doi.org/10.1007/s11229-019-02376-6

Ward, D., Silverman, D., \& Villalobos, M. (2017). Introduction: The varieties of enactivism. Topoi, 36, 365-375

Weber, A. \& Varela, F. J. (2002). Life after Kant: Natural purposes and the autopoietic foundations of biological individuality. Phenomenology and Cognitive Sciences, 1, 97-125 
Whitehead, A. N. (1925). Science and the modern world. The Free Press.

Whitehead, A. N. (1978). Process and reality: Corrected edition. The Free Press.

Williams, R. R. (1992). Recognition: Fichte and Hegel on the Other. State University of New York Press.

Williams, R. R. (1997). Hegel's ethics of recognition. University of California Press.

Yolton, J. W. (1967). Review of 'The phenomenon of life: Towards a philosophical biology' (by Hans Jonas). Journal of Philosophy, 68, 254-258

Publisher's note Springer Nature remains neutral with regard to jurisdictional claims in published maps and institutional affiliations. 